\title{
Coronary artery bypass surgery in a patient with Kartagener syndrome: a case report and literature review
}

\author{
loannis Bougioukas ${ }^{1}$, Dimitrios Mikroulis ${ }^{1}$, Bernhard Danner ${ }^{2}$, Lukman Lawal ${ }^{1}$, Savvas Eleftheriadis ${ }^{3}$, \\ George Bougioukas', Vassilios Didilis ${ }^{1 *}$
}

\begin{abstract}
Kartagener syndrome consists of congenital bronchiectasis, sinusitis, and total situs inversus in half of the patients. A patient diagnosed with Kartagener syndrome was reffered to our department due to 3-vessel coronary disease. An off-pump coronary artery bypass operation was performed using both internal thoracic arteries and a saphenous vein graft. We performed a literature review for cases with Kartagener syndrome, coronary surgery and dextrocardia. Although a few cases of dextrocardia were found in the literature, no case of Kartagener syndrome was mentioned.
\end{abstract}

\section{Introduction}

In 1606 Hieronymous Fabricious described situs inversus, while in 1643 Marco Severino described dextrocardia [1]. Situs inversus is a rare congenital disorder with an incidence of 1:10000, in which the major visceral organs are reversed from left to right in a mirror image of the normal condition [2]. Kartagener syndrome consists of congenital bronchiectasis, dextrocardia and sinusitis [2].

A patient with Kartagener's syndrome and three-vessel coronary disease was referred to our department for bypass surgery. We searched the literature about the Kartagener's syndrome in order to find references about the choice of conduits and the position of the surgeon in patients with mirror-image appearance of the heart. Several cases of surgical coronary revascularization in patients with dextrocardia have been reported in the literature, but no case was referred as Kartagener's syndrome. We report a case of a patient with Kartagener's syndrome with total situs inversus, bronchiectasis, chronic respiratory disease and three-vessel coronary disease, being treated in our institute with coronary surgery using both internal thoracic arteries. To the best of our knowledge this is the first report of coronary surgery in a patient with Kartagener syndrome.

\footnotetext{
* Correspondence: vdidilis@med.duth.gr

'Dpt. of Cardiothoracic Surgery, University Hospital Alexandroupolis, 68100, Greece

Full list of author information is available at the end of the article
}

\section{Case Report and Review}

A 56 year-old Caucasian male patient was admitted to our department for scheduled coronary artery bypass due to three-vessel coronary disease. The patient was already diagnosed as Kartagener syndrome with total situs inversus and azoospermia (patient had no children). A CT scan of the thorax showed bronchiectasis of the lungs and dextrocardia (fig. 1). The coronary angiography was performed without particular difficulties and revealed a proximal stenosis of $90 \%$ in the left anterior descending artery (LAD), a proximal stenosis of $90 \%$ in the circumflex artery and a stenosis of $99 \%$ between the proximal and middle part of the right coronary artery. The ejection fraction was normal and the aortic valve was competent. A spirometry was performed which revealed a reduction of the Forced Expiratory Volume, with a FEV1 of $1.44 \mathrm{~L}$ (40.6\% of predicted value) and a reduction of the Forced Vital Capacity, with a FVC of $1.80 \mathrm{~L}$ (38.7\% of the predicted value). Due to the patient's severe pulmonary disease an offpump operation was decided.

The chest was entered through a median sternotomy, with the surgeon standing on the left side of the patient. The heart had an exact mirror image of a normally positioned heart and showed a good contractility. Both internal mammary arteries (IMAs) and a saphenous vein graft (SVG) were harvested. The LAD was opened and grafted with the left internal mammary 


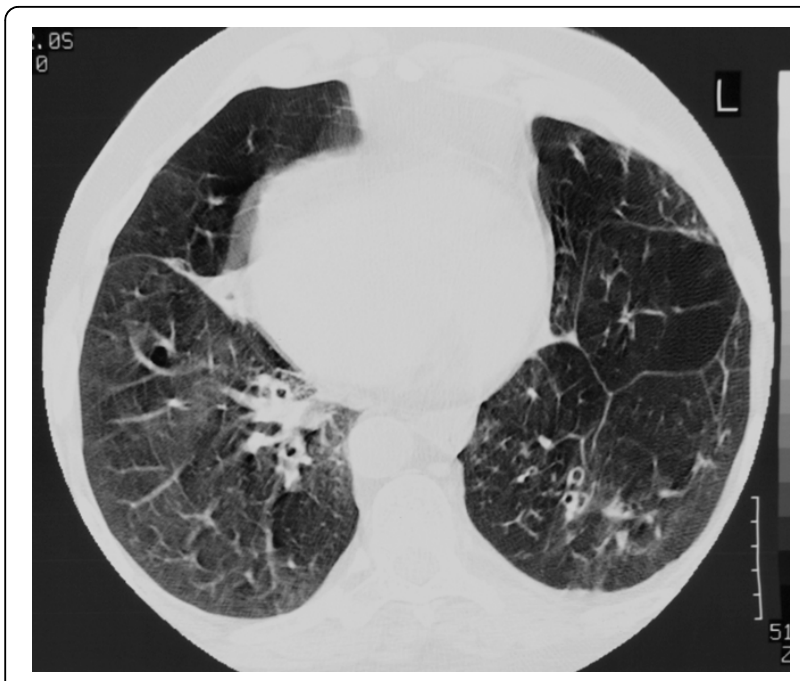

Figure $1 \mathrm{CT}$ scan of the thorax showing dextrocardia and bronchiectasis of the lungs.

artery (LIMA). Then the first obtuse marginal branch of the circumflex artery was grafted with right internal mammary artery (RIMA). Finally, the posterior descending artery (PDA) was grafted with the saphenous vein graft. The proximal anastomosis of the vein graft was then performed on the ascending aorta. After haemostasis, the chest was closed in routine fashion. The patient was extubated six hours later and remained in the Intensive Care Unit for three days due to his respiratory disease and increased volume of secretions. He was discharged from the hospital on the $10^{\text {th }}$ postoperative day.

\section{Discussion}

Kartagener's syndrome is characterized by the triad of bronchiectasis, sinusitis and situs inversus, and is also combined with abnormalities of the cilia of the respiratory epithelium. Some male patients with Katagener's syndrome also have sterility due to dyskinesia of the spermatozoa [2].

Total situs inversus is a rare condition which does not preclude long-term survival. Patients with dextrocardia and coronary disease may present for coronary bypass surgery. The mirror-image site of the heart and the great vessels does not impose a problem for carrying out a normal coronary artery bypass grafting operation, as it can be seen in the literature.

Saad et al reviewed the literature for coronary surgery in patients with dextrocardia, dealing with the position of the surgeon [3]. We reviewed the literature in order to ascertain the conduit choice of each surgeon, especially concerning grafting of the left anterior descending artery (Table 1).

Most of the authors preferred to graft the LAD with the right internal mammary artery, as the mirror-image appearance of the heart offers the convenience of using this arterial graft.

Seedio et al. reported a series of two patients [4]. In one case they used LIMA as a free graft to graft the LAD. Tabry et al. anastomosed the free LIMA to the RIMA and then they grafted the LIMA to the first diagonal branch and the LAD [5]. Kuwata et al. harvested both internal mammary arteries and both radial arteries, skeletonized the LIMA and managed to use it in-situ to graft the LAD [6]. Chakravarthy et al. reported two cases [7]. In the first case, they used LIMA in-situ to graft the LAD, whereas in the second case they used the RIMA. Yamashiro et al. used both IMAs and the radial artery, which was anastomosed to the LIMA and then to the second obtuse marginal branch (OM2) and PDA in a sequential manner [8]. RIMA was anastomosed to the LAD and LIMA grafted the OM1 branch. In older reports (Grey and Cooley, Irvin, Yamaguchi, Astudillo, Nomoto) saphenous vein grafts were exclusively used [9-13].

In our case the use of the left internal mammary artery to graft the left anterior descending artery was feasible, as the stenosis of the vessel was proximal and the length of the arterial conduit imposed no technical difficulty. We preferred the use of the LIMA to the LAD as the literature has strongly proven the excellent results of this anastomosis [14]. RIMA was skeletonized and used to graft the obtuse marginal branch of the circumflex artery. Finally, performing the operation "offpump" did not constitute a problem in our case, as the patient was haemodynamically stable throughout the procedure allowing us to have access to all coronary vessels, without the need of conversion to "on-pump" operation, as occurred in the case of Bonde and Campalani [15]. The use of cardiopulmonary bypass was omitted in our patient because of his poor respiratory function.

\section{Conclusion}

Situs inversus with mirror-image of the heart is a rare condition, which eventually every cardiac surgeon might have to deal with. The position of the surgeon depends mainly on the surgeon's choice. The use of the RIMA seems to be the easier way to graft the LAD, but when the lesion of the LAD is proximal LIMA can also be used to graft the LAD. In patients with Kartagener's syndrome and severe respiratory disease, off-pump bypass grafting could be performed. 
Table 1 Literature review of coronary surgery in dextrocardia patients

\begin{tabular}{|c|c|c|c|}
\hline Authors & Operation & Grafts used & Comments \\
\hline Grey, Cooley (1981)[9] & $\begin{array}{l}\text { 1. } C A B G \times 5 \\
\text { 2. } C A B G \times 2 \\
\text { 3. } C A B G \times 2\end{array}$ & SVGS & \\
\hline Irvin (1982)[10] & CABGX3 & SVGs & \\
\hline \multicolumn{4}{|l|}{ Yamaguchi (1990)[11] } \\
\hline Astudillo (1993)[12] & CABG & SVG & \\
\hline Nomoto (1997)[13] & CABG & SVG & LM disease \\
\hline Seddio (1999)[4] & $\begin{array}{l}\text { 1. } C A B G \times 1 \\
\text { 2. } C A B G \times 1\end{array}$ & $\begin{array}{l}\text { RIMA } \\
\text { LIMA }\end{array}$ & $\begin{array}{l}\text { RIMA to } L A D \\
\text { Free LIMA to LAD }\end{array}$ \\
\hline Wong, Chong (1999)[16] & CABGX3 & RIMA, SVGS & \\
\hline Totaro (2001)[17] & CABG $\times 3$ & RIMA, SVGs & \\
\hline Tabry (2001)[5] & CABG $\times 4$ & RIMA, free LIMA, SVG & RIMA to free LIMA to D1 and LAD, RIMA to OM1 to OM2, SVG to PDA \\
\hline Naik (2002)[18] & $C A B G \times 2$ & RIMA, SVG & \\
\hline Erdil (2002)[19] & CABG $\times 2$ & RIMA, SVG & \\
\hline Stamou (2003)[20] & $C A B G \times 2$ & RIMA, SVG & \\
\hline Chui, Sarkar (2003)[21] & $C A B G \times 2$ & RIMA, RA & \\
\hline Bonde, Campalani (2003)[15] & $C A B G \times 2$ & RIMA, SVG & \\
\hline Bonanomi (2004)[22] & $C A B G \times 2$ & RIMA, SVG & \\
\hline Abdullah, Mazalan (2004)[23] & CABG $\times 3$ & SVGS & \\
\hline Kuwata (2004)[6] & CABGX5 & $\begin{array}{l}\text { Both IMAs } \\
\text { Both RAs }\end{array}$ & In situ LIMA to LAD \\
\hline Poncelet (2006)[24] & CABG $\times 3$ & $\begin{array}{l}\text { Both IMAs } \\
\text { GEA }\end{array}$ & \\
\hline Ennker (2006)[25] & CABGX2 & RIMA & \\
\hline Karimi (2007)[26] & $\begin{array}{l}\text { 1. } C A B G \times 3 \\
\text { 2. } C A B G \times 4\end{array}$ & $\begin{array}{l}\text { RIMA, SVGS } \\
\text { RIMA, SVGS }\end{array}$ & \\
\hline Pego-Fernadez (2007)[27] & CABG $\times 5$ & RIMA, SVGs & \\
\hline Saadi (2007)[28] & CABG $\times 3$ & RIMA, SVGs & \\
\hline Chakravarthy (2008)[7] & $\begin{array}{l}\text { 1. } C A B G \\
\text { 2. CABG }\end{array}$ & $\begin{array}{l}\text { LIMA, RA, SVG } \\
\text { RIMA, SVG }\end{array}$ & In situ LIMA to LAD \\
\hline Saad (2009)[3] & CABGX3 & RIMA,SVGs & \\
\hline Yamashiro (2009)[8] & CABG $\times 4$ & Both IMAs, RA & RIMA to LAD, LIMA to OM1, LIMA to RA to OM2 to PDA \\
\hline
\end{tabular}

\section{Abbreviations}

CT: Computed Tomography; FEV1: Forced Expiratory Volume in 1 second; FVC: Forced Vital Capacity; LAD: Left Anterior Descending artery; OM: Obtuse Marginal branch; PDA: Posterior Descending Artery; LIMA: Left Internal Mammary Artery; RIMA: Right Internal Mammary Artery; SVG: Saphenous Vein Graft.

\section{Author details}

'Dpt. of Cardiothoracic Surgery, University Hospital Alexandroupolis, 68100, Greece. ${ }^{2}$ Dpt of Cardiovascular and Thoracic Surgery, University Hospital Goettingen, Germany. ${ }^{3}$ Dpt. of Anesthesiology. University Hospital Alexandroupolis, 68100, Greece.

\section{Authors' contributions}

Author's contributions: IB was the author. LL, BD and DM contributed to literature research. VD was the surgeon and supervisor. SE was the anesthetist. GB made corrections and consultation. All authors read and approved the final manuscript.

\section{Competing interests}

The authors declare that they have no competing interests.

Received: 27 April 2010 Accepted: 26 August 2010

Published: 26 August 2010

\section{References}

1. Cleveland M: Situs in versus viscerum: anatomic study. Arch surg 1926, 13(343).

2. Leigh M, Pittman J, Carson J, Ferkol T, Dell S, Davis S, Knowles M, Zariwala M: Clinical and genetic aspects of primary ciliary dyskinesia/ Kartagener syndrome. Genet med 2009, 11(7):473-487.

3. Saad R, Badr A, Goodwinm A, Dunning J: Should you stand on the left or the right of a patient with dextrocardia who needs coronary surgery? Interact Cardiovasc Thorac Surg 2009, 9:698-702.

4. Seddio F, Colagrande L, Pellegrino A, De Paulis R, Bassano C, Chiariello L: Myocardial revascularization in dextrocardia with situs inversus. $G$ Ital Cardiol 1999, 29(10):1222-6.

5. Tabry I, Calabrese J, Zammar H, Abou-Kasem K, Akeilan H, Gharbieh N, Zinati H, Noureddine W, el-Hout A, Tayah M, Khalidy L, Yaghi M: Case report: off-pump total myocardial revascularization for dextrocardia and situs inversus. Heart Surg Forum 2001, 4(3):251-3.

6. Kuwata T, Ueda T, Sakaguchi H, Nagasaka S, Taniguchi S: Off-pump quintuple coronary artery bypass grafting for situs inversus totalis. Jpn J Thorac Cardiovasc Surg 2004, 52(10):473-5.

7. Chakravarthy M, Jawali V, Nijagal D: Off-Pump Coronary Artery Bypass Surgery in Dextrocardia: A Report of Two Cases. Ann Thorac Cardiovasc Surg 2008, 14(3):187-191.

8. Yamashiro S, Iha K, Akasaki M, Toru Uezu, Ryo Ikemura, Isao Nishijima: Emergency off-pump complete arterial revascularization in a patient with dextrocardia. Gen Thorac Cardiovasc Surg 2009, 57:625-628. 
9. Grey D, Cooley D: Dextrocardia with situs inversus totalis: Cardiovascular surgery in three patients with concomitant coronary artery disease. Cardiovascular Diseases, Bulletin of the Texas Heart Institute 1981, 8(4).

10. Irvin R, Ballenger J: Coronary artery bypass surgery in a patient with situs inversus. Chest 1982, 81:380-381.

11. Yamaguchi T, Kikuchi S, Doi H, Watanabe A, Ebuoka M: Coronary artery bypass in dextrocardia with situs inversus totalis-a case report. Nippon Kyobu Geka Gakkai Zasshi 1990, 38(9):1538-42.

12. Astudillo R, Escudero X, Farell J, Ariza H, González Carmona VM, Tello R: Atherosclerotic ischemic cardiopathy in patients with dextrocardia in situs viscerum inversus. Arch Inst Cardiol Mex 1993, 63(2):123-6.

13. Nomoto T, Ueda Y, Ogino H, Sugita T, Morioka K, Matsubayashi K: Emergent coronary artery bypass grafting in a patient with mirror-image dextrocardia. Kyobu Geka 1997, 50(9):785-8.

14. Mack M, Osborne J, Shennib H: Arterial graft patency in coronary bypass grafting: what do we really know? Ann Thorac Surg 1998, 66:1055-1059.

15. Bonde P, Campalani G: Myocardial revascularization for situs inversus totalis and dextrocardia. Interactive Cardiovascular and Thoracic Surgery 2003, 2:486-488

16. Wong PS, Chong CL: Multiple coronary artery bypass grafting in dextrocardia: case report. Med J Malaysia 1999, 54(4):514-6.

17. Totaro P, Coletti G, Lettieri C, Pepi P, Minzioni G: Coronary artery bypass grafts in a patient with isolated cardiac dextroversion. Ital Heart J 2001, 2(5):394-6.

18. Naik MJ, Chua YL, Ding ZP, Lau KW: Coronary artery bypass grafts in situs inversus. J Cardiovasc Surg (Torino) 2002, 43(2):181-4.

19. Erdil N, Cetin L, Sener E, Ufuk D, Cemal S: Situs Inversus and Coronary Artery Disease. Asian Cardiovasc Thorac Ann 2002, 10:53-4.

20. Stamou S, Bafi A, Kapetanakis E, Lowery R, Pfister A, Dullum M, Boyce S, Corso P: Beating Heart Surgery in a Patient with Dextrocardia and Complete Situs Inversus. J Card Surg 2003, 18:170-172.

21. Chui W, Sarkar P: Coronary artery bypass grafting in dextrocardia with situs inversus totalis. J Cardiovasc Surg (Torino) 2003, 44(5):617-9.

22. Bonanomi G, Kostov D, Zenati M: Emergent off-pump complete myocardial revascularization in dextrocardia. J Cardiovasc Surg (Torino) 2004, 45(1):31-3.

23. Abdullah F, Mazalan S: Off-pump coronary artery bypass grafting in a high-risk dextrocardia patient: a case report. Heart Surg Forum 2004, 7 E186-E188.

24. Poncelet $A$, Dion $R$, Lengele $B$, Noirhomme $P$ : Complete arterial revascularization in coronary artery bypass grafting in a patient with solitus inversus totalis. J Cardiovasc Surg (Torino) 2006, 47(4):477-9.

25. Ennker I, Pietrowski D, Ennker J: Off-pump myocardial revascularization in an octogenarian patient with dextrocardia and situs inversus. Cardiovascular Journal Of South Africa 2006, 17(5):257-258.

26. Karimi A, SalehiOmran A, Ahmadi H, Yazdanifard P: Total myocardial revascularization for situs inversus totalis with dextrocardia: a case report. Journal of Medical Case Reports 2007, 1:18.

27. Pego-Fernandes PM, de Serro-Azul JB, Matheus F, Maehara BS: Myocardial revascularization in a patient with situs inversus totalis. Arg Bras Cardiol 2007, 88(5):e103-6.

28. Saadi E, Dussin L, Nicolao A, Zago A: Coronary artery bypass grafting in a patient with situs inversus totalis and dextrocardia. Rev Bras Cir Cardiovasc 2007, 22(3):346-348.

doi:10.1186/1749-8090-5-68

Cite this article as: Bougioukas et al:: Coronary artery bypass surgery in a patient with Kartagener syndrome: a case report and literature review. Journal of Cardiothoracic Surgery 2010 5:68.

\section{Submit your next manuscript to BioMed Central and take full advantage of:}

- Convenient online submission

- Thorough peer review

- No space constraints or color figure charges

- Immediate publication on acceptance

- Inclusion in PubMed, CAS, Scopus and Google Scholar

- Research which is freely available for redistribution

Submit your manuscript at www.biomedcentral.com/submit
Biomed Central 